Noelia Carrasco - Ricardo Salas, Inflexiones y dilemas ético - políticos del capitalismo en el Centro Sur de Chile. A propósito de la globalización forestall / Inflections and ethical - political dilemmas of the capitalism in the Center South of Chile. About forest globalization, Revista Izquierdas, 27, abril 2016, ISSN 0718-5049, pp. 105-123

\title{
Inflexiones y dilemas ético - políticos del capitalismo en el Centro Sur de Chile. A propósito de la globalización forestal
}

\section{Inflections and ethical - political dilemmas of the capitalism in the Center South of Chile. About forest globalization}

\author{
Noelia Carrasco Henríquez* \\ Ricardo Salas Astrain
}

\footnotetext{
* Chilena, autora principal. Antropóloga, especialista en antropología económica aplicada, Académica de la Universidad de Concepción. Este trabajo se enmarca dentro de los siguientes proyectos de investigación: Proyecto Fondecyt 1150770 "Imaginarios del desarrollo sustentable y ecología política del territorio: conflictos socioambientales y disputas en territorios forestales costeros del Biobío y el Maule" y Anillos SOC 1404 "Dinámicas naturales, espaciales y socio-culturales: perspectivas sobre los conflictos socio-ambientales en territorios forestales de Chile, 1975-2014”, noeliacarrasco@udec.cl

${ }^{* *}$ Chileno, coautor. Filósofo, experto en interculturalidad, ética y política, Académico del Departamento de Sociología y Ciencia Política de la Universidad Católica de Temuco e Investigador Responsable del Núcleo de Investigación en Estudios Interculturales e Interétnicos de dicha Universidad, rsalas @uct.cl
} 
Noelia Carrasco - Ricardo Salas, Inflexiones y dilemas ético - políticos del capitalismo en el Centro Sur de Chile. A propósito de la globalización forestall / Inflections and ethical - political dilemmas of the capitalism in the Center South of Chile. About forest globalization, Revista Izquierdas, 27, abril 2016, ISSN 0718-5049, pp. 105-123

\section{Resumen:}

El escenario del capitalismo global traducido en "manejo forestal sustentable" adquiere hoy especial complejidad ético-política en la diversidad económica y cultural del Centro Sur de Chile. Tras un acontecimiento mediático que evidencia las comprensiones racistas que marcan la convivencia interétnica en el territorio, se revelan algunas limitaciones del principal sistema de certificación que controla la sustentabilidad del mercado forestal. El caso estudiado, permite analizar los desafíos locales de la globalización del capitalismo global en Chile desde las miradas de la antropología sociocultural y la filosofía política e intercultural.

Palabras clave: Centro Sur de Chile, Capitalismo Global, Diversidad Cultural, Sustentabilidad, Certificación forestal.

\begin{abstract}
:
The scenario of global capitalism translated into "sustainable forest management" acquires today special ethical and political complexity in the economic and cultural diversity of South Central Chile. After a media event that puts in evidence the racist understandings that highlight the inter-ethnic coexistence in the country, some limitations of the main certification system that controls the sustainability of forest market are revealed. The case in study, allows to analyze the local challenges of of globalization of the capitalism in Chile from the sight of sociocultural anthropology and political and intercultural philosophy.
\end{abstract}

Keywords: Center South of Chile, Global Capitalism, Cultural Diversity, Sustainability, Forest Certification.

Recibido: 18 noviembre 2015

Aceptado: 9 enero 2016

\section{Introducción}

La complejidad de las relaciones sociales en el territorio centro sur de Chile es comprendida aquí, como el reflejo de las condiciones de desigualdad económica y cultural que en conjunto determinan la cotidianeidad de las relaciones interétnicas e interculturales asimétricas. Bajo tales condiciones, que son históricas, socioeconómicas y socioculturales al mismo tiempo, proponemos examinar el contexto y las claves de sentido en que se vivencia la conflictividad social y económica, a partir de un proceso clave en la construcción actual del territorio. Para ello, proponemos relevar el rol de los discursos y prácticas globales del capitalismo "sustentable" que se ve confrontado con las resistencias y expectativas de comunidades mapuche y movimientos ambientalistas y ciudadanos que buscan reconocimiento y autonomía en la definición propia de sus procesos de desarrollo. En este marco se hace pertinente la discusión abierta por el antropólogo C. Hale (2006) acerca del rol que le cabe a la antropología y a las ciencias sociales como discurso crítico y discurso militante. Esta cuestión se relaciona claramente con nuestro estudio en cuanto implica consideraciones ético-políticas acerca del modo como el conocimiento científico social responde desde su propia lógica a las complejas tramas que atraviesa el mundo sociocultural en el Chile neoliberal. 
Noelia Carrasco - Ricardo Salas, Inflexiones y dilemas ético - políticos del capitalismo en el Centro Sur de Chile. A propósito de la globalización forestall / Inflections and ethical - political dilemmas of the capitalism in the Center South of Chile. About forest globalization, Revista Izquierdas, 27, abril 2016, ISSN 0718-5049, pp. 105-123

Luego de la descripción del caso que ilustrará algunos de los matices de la globalización del capitalismo a través del denominado "manejo forestal sustentable", se fundamentará la construcción del problema científico social utilizando perspectivas teórico - metodológicas que permiten analizar desde la antropología, la ciencia política y la filosofía social aquello que comprendemos como la vivencia de la economía política capitalista global en contextos locales específicos. La hipótesis que sostiene este acercamiento establece que las actuales dimensiones y contenidos socioculturales de la economía y sus alcances pueden comprenderse sólo si prestamos adecuada atención al modo en que los sujetos se apropian de significados y premisas que orientan al comportamiento cotidiano y sustentan éticamente las prácticas que en la actualidad rigen el orden y la vivencia de las relaciones ${ }^{1}$. Cuando tales significados y premisas son resueltos y justificados desde el control ideológico y político global, su capacidad de integrar intereses y expectativas se desvanece, revelando la necesidad de revisar la comprensión de lo que hasta ahora se ha oficializado como manejo forestal sustentable.

Los resultados de esta reflexión, basada en antecedentes empíricos debidamente referidos, reafirman la importancia del examen minucioso de los actuales procesos económicos, políticos y culturales que organizan la realidad del territorio. Para contribuir a ello se analizan los alcances de la globalización de la economía en los escenarios locales, incluyendo la pregunta por el rol de las expresiones locales en dicha configuración global. El caso analizado permite avizorar que este rol se enmarca en una ética del reconocimiento de la diversidad caracterizada por abrir espacios de diálogo sobre la diversidad cultural dentro de los límites del mercado, y se materializan en acciones y prácticas que parecen renovar el escenario pero finalmente, no implican transformaciones efectivas en función de las complejidades que progresivamente adquiere la realidad socioeconómica y política del territorio ${ }^{2}$.

\section{Antecedentes del problema de investigación}

Para dar cuerpo empírico al análisis, deconstruiremos desde la mirada de la etnografía multilocal $^{3}$, una situación específica que nos permitirá esbozar una discusión en torno a algunos componentes de la trama polifacética de la diversidad económica y cultural del Centro Sur de Chile, compuesta de actores, discursos, prácticas y marcos de referencia ético políticos. Comprendemos que esta trama refleja hoy las expresiones del capitalismo global en el territorio, debido a que manifiesta el modo en que las normas del mercado internacional regulan el comportamiento de los sujetos e inciden en la vida cotidiana. Para la construcción de esta etnografía, se consideró un conjunto de perspectivas e hitos que en la descripción van hilándose y construyendo un relato coherente. Las perspectivas consideradas fueron: a) las normas internacionales - estándares y políticas que gobiernan la

\footnotetext{
${ }^{1}$ Santiago Castro - Gómez y Ramón Grosfoguel, "Prólogo. Giro decolonial, teoría crítica y pensamiento heterárquico", Santiago Castro - Gómez y Ramón Grosfoguel (Eds), El giro decolonial. Reflexiones para una diversidad epistémico más allá del capitalismo global. Bogotá, Siglo del Hombre Editores, 2007, 9-24.

${ }^{2}$ Ricardo Salas, Ética intercultural, Quito, Abya-Yala, 2006.

3 George, E. Marcus, "Etnografía en/del sistema mundo. El surgimiento de la etnografía multilocal", Alteridades Vol. $11 \mathrm{~N}^{\circ}$ 22, 2001.
} 
Noelia Carrasco - Ricardo Salas, Inflexiones y dilemas ético - políticos del capitalismo en el Centro Sur de Chile. A propósito de la globalización forestall / Inflections and ethical - political dilemmas of the capitalism in the Center South of Chile. About forest globalization, Revista Izquierdas, 27, abril 2016, ISSN 0718-5049, pp. 105-123

construcción contemporánea del manejo forestal sustentable -, b) las organizaciones mapuche - las que inician con el requerimiento a la suspensión de vuelos y las que denuncian luego las expresiones racistas del ejecutivo forestal, c) las instituciones nacionales que responden a la solicitud de las comunidades mapuche de acuerdo a un cuerpo jurídico que reconoce y legitima este tipo de derechos indígenas, d) el representante de la empresa posteriormente denunciado por la organización mapuche, e) la organización de ingenieros forestales que, con su denuncia, refuerza la importancia del caso analizado y f) la del sistema de certificación internacional que responde a las denuncias con requerimientos específicos a la empresa en cuestión. El tratamiento etnográfico de estas perspectivas se enriquece a su vez con la descripción de los hitos que estructuran al caso, entre los cuales se destacan: a) la solicitud de las comunidades por la suspensión de los vuelos y la respuesta de la institucionalidad nacional responsable, b) las expresiones del representante de la empresa forestal a través de las redes sociales, c) la reacción de la organización mapuche y la organización de ingenieros forestales ante las expresiones racistas y su interpelación al sistema de certificación forestal, d) la reacción y respuesta del sistema de certificación forestal ante la denuncia recibida.

Las fuentes utilizadas responden a la perspectiva de la etnografía contemporánea que tributa a los análisis críticos de la modernidad, de acuerdo a la cual "la cibercultura está creando un conjunto de verdades "tecnológicas del ser" que van más allá del ser como máquina; y la productividad cultural de estas nociones solamente puede ser valorada etnográficamente"4. Al mismo tiempo, se integran los planteamientos de la reflexión metodológica ya instalada en la antropología, sobre los aspectos centrales de la etnografía virtual $^{5}$, entre los cuales se destaca la atención a los lenguajes y sentidos de la comunicación, la reconfiguración de los roles en los escenarios virtuales y los desafíos ético-políticos del manejo de materiales de esta índole.

El marco temporal de este estudio refiere particularmente a la última década que es el periodo en que se ha iniciado un abordaje sistemático a las implicancias socioculturales y medioambientales del tipo de desarrollo implementado en la Macrorregión Sur y en la que se inician, en forma sistemática, procesos de certificación forestal que ponen en tensión a diversos actores que habitan el territorio. No se trata de un estudio del despliegue del neoliberalismo en Chile, sino más bien de las lecturas de la diversidad cultural y el discurso racista que se elaboran desde los lenguajes del capitalismo global. Para abordar este análisis, describiremos una situación que implica a actores de comunidades mapuche, de organismos públicos, de empresas privadas y a una norma de certificación forestal internacional. Esta última, es analizada aquí como un actor clave en la configuración de la complejidad de las relaciones interétnicas entre comunidades mapuche y empresas forestales en los últimos años, no precisamente por su impacto en la superación de los problemas que marcan a sus relaciones sino más bien por sus efectos en la renovación del lenguaje y por constituir un complejo "deber ser" para las empresas una vez que adoptan sus principios. Por otra parte, el caso permite ilustrar también las naturalezas diversas de los

\footnotetext{
4 Arturo Escobar, "Bienvenidos a cyberia. Notas para una antropología de la cibercultura", Revista de Estudios Sociales N²2, 2005, 15-35.

5 Daniel Dominguez, Anne Beaulieu, Adolfo Estalella, Edgar Gómez, Bernt Schnettler y Rosie Road, "Etnografía Virtual", Forum Qualitative Sozialforschung / Forum: Qualitative Social Research, 8 (3).
} 
Noelia Carrasco - Ricardo Salas, Inflexiones y dilemas ético - políticos del capitalismo en el Centro Sur de Chile. A propósito de la globalización forestall / Inflections and ethical - political dilemmas of the capitalism in the Center South of Chile. About forest globalization, Revista Izquierdas, 27, abril 2016, ISSN 0718-5049, pp. 105-123

discursos que fluyen en el territorio en torno a la economía y el desarrollo, proporcionando desde ahí un marco comprensivo de las tensiones y los cauces que adoptan los conflictos ${ }^{6}$. Finalmente, cabe destacar que el caso muestra las características de la gobernanza del mercado global hoy enmarcado en la "sustentabilidad", en contextos locales específicos, revelando sentidos asignados y marcos ético - políticos implicados ${ }^{7}$.

\section{La complejidad "mediática" de la trama}

Los diversos proyectos de inversión en el territorio estudiado, desde la construcción de las represas en el alto Bío Bío, la autopista by pass Temuco, hasta la construcción del nuevo Aeropuerto en esta misma ciudad, han sido objeto de diversas controversias políticas, culturales y medioambientales en las que se manifiestan los intereses, expectativas y estereotipos que existen en la sociedad chilena, y que están lejos de generar consensos. En especial, la construcción de este último espacio aeronáutico ha quedado registrada en los documentos que reflejan las discusiones de las comunidades mapuches, de las instituciones del estado y de los intereses de los privados. Desde el mundo académico se ha iniciado la recopilación de estas polémicas político-culturales quedando registrado en diversos documentos públicos nacionales e internacionales y en los medios de prensa del país ${ }^{8}$.

La trama mediática actual se inicia cuando integrantes de comunidades mapuche cercanas al nuevo aeropuerto de la ciudad de Temuco, solicitaron a las autoridades de este controvertido espacio aeronáutico, la suspensión de los vuelos durante los días 19 y 20 de

\footnotetext{
${ }^{6}$ Noelia Carrasco, "Horizontes de la reflexividad etnográfica. Revelaciones y tensiones para el estudio antropológico del desarrollo en Chile", Tabula Rasa, Bogotá, 2010, 113-129.

${ }^{7}$ Ricardo Salas y Fabien Le Bonniec (eds.), Les mapuches à la mode. Modes d'existence et de resistance au Chili, en Argentine et au-delà, Paris, L'Harmattan, 2015.

${ }^{8}$ Se puede considerar entre otros antecedentes primarios para entender este conflicto que analizamos, en primer lugar las bases que no contemplan pertinente y adecuadamente los aspectos socio-culturales: http://www.concesiones.cl/proyectos/Documents/Aeropuerto\%20de\%20la\%20araucania/Bases\%20TR.pdf Una breve síntesis se encuentra en: Antecedentes del Conflicto aeropuerto en Quepe, preparado por la Asociación Ayun Mapu, Informe Alternativo sobre la situación de discriminación racial que afecta al pueblo mapuche, Ginebra, agosto 2009, pp. 19-22. Recuperado en:

http://www2.ohchr.org/english/bodies/cerd/docs/ngos/Informe_Mesa_Mapuche_chile_CERD75.pdf Resolución de la Corte de Apelaciones acerca del reclamo de la comunidad indígena Juan Antonio Antimán http://www.observatorio.cl/sites/default/files/biblioteca/doc_trabajo_numero4-pueblos-indigenas-glob-yterri.pdf

Véase asimismo la sentencia judicial de la Corte Suprema por el reclamo de las seis comunidades indígenas aledañas, en http://revistafiscalia.mop.cl/sentneciasjudiciales/Documents/Sentencia_Convenio_169.pdf Asimismo en el año 2010, informaba el Diario Austral los retrasos en la construcción y los conflictos en juego: http://www.australtemuco.cl/prontus4_noticias/site/artic/20100813/pags/20100813003320.html Ver también el estudio de Richard Caifal "El aeropuerto internacional y la comunidad indígena Ricardo Rayin" en Documento del Observatorio ciudadano, Pueblos indígenas, Globalización y Territorio, 2006, pp. 38-47. Recuperado en http://www.observatorio.cl/sites/default/files/biblioteca/doc_trabajo_numero4-pueblosindigenas-glob-y-terri.pdf

José Bonivento y Francisco Maturana, Contextos complejos, Actores locales, Políticas Públicas. El caso del aeropuerto de Temuco, en Revista Iberoamericana de Estudios Municipales, 11, 2015, pp. 43-61.
} 
Noelia Carrasco - Ricardo Salas, Inflexiones y dilemas ético - políticos del capitalismo en el Centro Sur de Chile. A propósito de la globalización forestall / Inflections and ethical - political dilemmas of the capitalism in the Center South of Chile. About forest globalization, Revista Izquierdas, 27, abril 2016, ISSN 0718-5049, pp. 105-123

diciembre del $2014^{9}$. Su principal argumento era la realización de una ceremonia religiosa, en la que se reúnen personas de diversas comunidades y en la que los ruidos de los aviones al despegar y aterrizar provocarían dificultades e incomodidad para el sentido religioso de la misma. El gobierno, a través de la Seremi de OO.PP de la región de la Araucanía y el propio aeropuerto, a través de la Dirección General de Aeronáutica Civil (DGAC) acogieron tal singular requerimiento, y según lo expusieron en los medios de comunicación durante las semanas siguientes, "la Resolución de Calificación Ambiental (RCA), es el instrumento legal que anticipa este tipo de situaciones y, por lo tanto, en él está contemplado cómo se atienden estos requerimientos, y señala que deberían desviarse los vuelos cuando existen este tipo de ceremonias religiosas. No se trata sólo de voluntad, hay un cuerpo legal al cual ceñirse”, se puntualiza en un diario de circulación nacional (www.latercera.com, 25/11/14).

Este requerimiento se enmarca así en la trama socio-cultural de los territorios históricos habitados por mapuche, en la que conviven distintas ideas, creencias y prácticas sobre el mundo, la naturaleza, la vida, la espiritualidad, el tiempo, el territorio y el desarrollo. Es la trama polifacética de la globalización a escala local ${ }^{10}$, donde encontramos nuevos ejemplos de las condiciones existentes para la implementación de grandes proyectos de inversión en territorios definidos por la diversidad cultural, y que exige claramente una revisión de las condiciones de diálogo intercultural e interétnico.

Aunque para algunos esta situación respecto de los vuelos en este nuevo aeropuerto ha sido motivo para expresar insultos y descalificaciones hacia las comunidades indígenas, para otros resulta relevante porque es el ejercicio de un derecho que éstas tienen de contar con todas las condiciones necesarias para desarrollar adecuadamente su ceremonia religiosa. Sobre este singular escenario político, nos dedicaremos a revisar las expresiones de rechazo y las respuestas ofensivas hacia las comunidades, procedentes de una persona que forma parte del equipo directivo de una empresa forestal comprometida con los principios globales de manejo forestal sustentable, representados por el Forest Stewardships Council (FSC). El foco del análisis va más allá de las ofensas y sobre todo, de la persona implicada, y se ubica especialmente en el rol del mercado global en la gestión de la discriminación y el trato indigno hacia los pueblos indígenas. Dicho análisis permite, a nuestro entender, mostrar y descubrir el alcance de las normas globales del mercado "sustentable" en la gestión de procesos locales, evidenciando el modo en que el capitalismo global se inyecta en los valores, en los lenguajes, en la intersubjetividad y se hace cotidiano.

$\mathrm{Si}$ bien en el último tiempo se han difundido nuevas investigaciones $\mathrm{e}$ interpretaciones sobre "el conflicto" y sus protagonistas ${ }^{11}$, aun es poco lo que sabemos

\footnotetext{
${ }^{9}$ Una breve opinión al respecto de los dos autores fue elaborada para el sitio web Observatoriodecide.cl, y se puede encontrar en la página http://observatoriodecide.cl/2014/12/16/de-aviones-nguillatunes-otros-dilemasetico-politicos-inflexiones-acerca-del-desarrollo-en-la-araucania/

${ }^{10}$ Marc Abeles, Antropología de la Globalización, Ediciones del Sol, Buenos Aires, 2012.

${ }^{11}$ Algunas referencias actuales son: Sandra López y Luis Nitrihual, Vidas de Papel. Negocio de la Madera y Conflicto Intercultural en Chile, Temuco, Editorial Universidad de la Frontera, 2014; Marcel Oppliger, Los chilenos olvidados. Hablan las víctimas del conflicto en La Araucanía, Santiago, Ril Editores, 2013; TitoTricot, Palabras de tierra: crónicas de resistencia mapuche, Santiago, Ceibo Ediciones, 2014; Héctor Llaitul y Jorge Arrate, "WEICHAN. Conversaciones con un weychafe en la prisión política”, Santiago, Ceibo
} 
Noelia Carrasco - Ricardo Salas, Inflexiones y dilemas ético - políticos del capitalismo en el Centro Sur de Chile. A propósito de la globalización forestall / Inflections and ethical - political dilemmas of the capitalism in the Center South of Chile. About forest globalization, Revista Izquierdas, 27, abril 2016, ISSN 0718-5049, pp. 105-123

sobre las interpretaciones racistas y discriminatorias que se viven hoy en el centro sur de Chile y las diversas formas que éstas adoptan. Si consideramos únicamente el análisis de Richards $^{12}$, podremos ver que desde una perspectiva socioantropológica las relaciones interculturales en el contexto de las luchas por los recursos naturales en estos territorios ponen en evidencia las formas en que las ideologías de la identidad y el desarrollo se reproducen y son reinterpretadas en el ámbito local, fuertemente asociadas a un racismo sistémico que se articula en el mismo proceso socioeconómico y político. En este sentido, podríamos interpretar que a través del reclamo las personas no sólo invalidan el derecho que puedan tener las comunidades a realizar su ceremonia en silencio, sino además refuerzan el sentido impropio que tendría este derecho, sobre la base de argumentos que evidencian la violencia y el resentimiento anidado históricamente en estas tierras.

Esto permite argumentar la tesis de un racismo cotidiano y radical, que encontró en la situación del aeropuerto una ocasión más para expresarse. Tras la noticia divulgada por el Diario La Tercera el día 25/11/14, se desplegó el siguiente chat, que ilustra esta situación:

(1) (ceremonia para pedir a Chao Ngnechén - Dios - por mejores cosechas)”... que cosecha..??? si no siembran ni una papa... todos se las dan...

(2) ... pretender que los demás suspendan sus viajes porque ellos no pueden concentrarse o que su Dios va a escuchar ruidos y no plegarias. Jajajajajajajajajajajajaja, que bueno el chiste.

\section{(3) Lo que tienen que pedir es educación y oportunidades de superarse, en vez de andar disfrazados de indios saltando como canguros....}

Todas estas interpretaciones muestran no sólo el sentido agresivo de la subestimación, sino también el sentido paternalista a partir del cual se establece el camino que las comunidades indígenas debieran seguir. Es decir, se trataría de una posición despectiva y arrogante, resabio de las creencias evolucionistas del siglo XIX y de las prácticas de colonización que se mantienen aún enquistadas en las actitudes de muchos chilenos y marcadamente presentes en usuales y convencionales conceptos de desarrollo. Esta posición, circula aun cuando es socialmente considerada como "políticamente incorrecta", y sus promotores - tal como podemos leer en los chats citados - la comparten con total impunidad en los medios electrónicos. Para muchos es quizá sólo un "modo de pensar" entre otros más que co habitan el territorio, pero su inocencia está siendo cada vez más cuestionada, sobre todo cuando interpela directamente los límites que las actuales éticas aplicadas (en este caso la del desarrollo) están dispuestas a aceptar como razonables o esperables de parte de altos ejecutivos de empresas forestales presentes en el territorio.

Ediciones, 2013; Patricia Richards, Race and the Chilean Miracle: Neoliberalism, Democracy and Indigenous Rights", Pittsburgh, University of Pittsburgh Press, 2013; Comunidad de Historia Mapuche, Ta iñfijkerakizuameluwün. Historia, colonialismo y resistencia desde el país Mapuche, Ediciones Comunidad de Historia Mapuche, 2012 (1ª Edición), 2013 (2da Edición).

${ }^{12}$ Ídem. 
Noelia Carrasco - Ricardo Salas, Inflexiones y dilemas ético - políticos del capitalismo en el Centro Sur de Chile. A propósito de la globalización forestall / Inflections and ethical - political dilemmas of the capitalism in the Center South of Chile. About forest globalization, Revista Izquierdas, 27, abril 2016, ISSN 0718-5049, pp. 105-123

La trama se fue posteriormente enriqueciendo más allá del requerimiento de las comunidades por la suspensión de vuelos para realizar con tranquilidad su ceremonial. El caso descrito permite mostrar cómo los nguillatunes, los aviones y la certificación forestal aparecen complejamente entrelazadas en los cotidianos del centro sur de Chile de hoy. Esta complejidad quedó en evidencia, cuando diversos actores adherentes al sistema FSC en el territorio tomaron registro de los dichos del ejecutivo forestal y denunciaron la situación ante el Directorio de FSC - Chile e Internacional, uno de los principales sellos de certificación forestal en el mundo.

El Forest Stewardship Council - socialmente conocido por su sigla FSC - es un sistema de certificación a escala mundial creado en la década de los ochenta, con el objetivo de instalar un nuevo concepto de "bosque bien manejado". Por sus contenidos, se transformó gradualmente en un estándar que no sólo regula el consumo de la madera y sus derivados, sino también las dinámicas locales de las grandes empresas forestales que, para optar y luego conservar el sello, deben responder al marco ideológico, tecnológico, científico y práctico que impone el estándar: el manejo forestal sustentable. A través de 10 principios y 56 criterios, además de un grueso número de indicadores, el estándar FSC introduce en la gestión de las empresas forestales un conjunto de orientaciones tanto para la producción como para la gestión de sus procesos asociados. Entre estos procesos se cuentan tanto el apoyo a iniciativas de desarrollo local, como el cumplimiento de los derechos de los trabajadores ${ }^{13}$ y de los derechos indígenas, incluyendo en ellos el resguardo de sus sitios de significación cultural y la gestión de conflictos asociados a la propiedad de la tierra.

El evento mediático se desencadena porque opiniones expresadas abiertamente en las redes sociales acerca de la eventual suspensión de los vuelos a propósito del nguillatun de las comunidades cercanas al aeropuerto, era la de un reconocido agente de la actividad forestal, Gerente General de una empresa certificada FSC, Director de la Corporación Chilena de la Madera - CORMA- en la región de la Araucanía y en periodos anteriores, Director de la Cámara Económica de FSC Chile. Emerge entonces el conflicto ya no sólo de opiniones sino entre interpretaciones, cuando dos planteamientos se oponen en un mismo sujeto y existe un ojo atento que lo captura y lo usa para denunciar, interpelar y exigir al FSC un gesto político importante en la historia de las relaciones entre las empresas forestales y las comunidades mapuche. Se detona así, la interpelación a un organismo representativo del capitalismo global, como es este estándar, para que ejerza un rol y cumpla su misión declarada en sus principios y criterios, particularmente en lo que respecta al reconocimiento y los derechos de los pueblos indígenas.

Una de las frases publicadas en las redes sociales era la siguiente: "No están enfermos sino que son frescos de raja. Todo porque el Estado les aguanta todo a estos

\footnotetext{
${ }^{13}$ En este ámbito, cabe señalar que los trabajadores constituyen un grupo de interés clave en los procesos de certificación. Su participación se canaliza a través de dos instancias centrales e imprescindibles en los procesos de auditoría: la entrevista con dirigentes de las organizaciones gremiales y la visita a las faenas forestales que realizan los cuerpos certificadores en que se verifica en terreno el cumplimiento o incumplimiento de los contenidos del estándar. Por otra parte, en el caso chileno se evidencia que a través de sus representantes, los trabajadores forestales participan hoy de instancias de diálogo forestal y de actualización de estándares. De acuerdo a sus propias referencias, todo este reconocimiento proviene de varios factores, entre los cuales se destaca la crisis del 2007 - que incluyó la muerte de un trabajador en manifestaciones en el entorno de una planta de celulosa - y el propio impulso de los sistemas de certificación.
} 
Noelia Carrasco - Ricardo Salas, Inflexiones y dilemas ético - políticos del capitalismo en el Centro Sur de Chile. A propósito de la globalización forestall / Inflections and ethical - political dilemmas of the capitalism in the Center South of Chile. About forest globalization, Revista Izquierdas, 27, abril 2016, ISSN 0718-5049, pp. 105-123

desgraciados", y compartir en el mismo posteo la noticia publicada por soytemuco.cl titulada "Mapuches quieren cancelar los vuelos el 19 y 20 de diciembre porque realizarán un guillatún", fue el paso en falso que desmantela esta ingrata pero cotidiana situación. Claramente, el participante de FSC en representación de la empresa forestal que dirige no había logrado comprender aún que hay incompatibilidades ideológicas y valóricas en su discurso y su actuar mediático, pero las organizaciones denunciantes si prestaron atención a esto, y así lo han declarado.

La Corporación Mapuche Pewün Kimun denuncia que este ejecutivo hace un uso recurrente de las redes sociales - específicamente Facebook - para difundir su pensamiento, el cual califican de racista, ofensivo e inaceptable. El 26 de noviembre de 2014, difunde en medios y redes sociales la denuncia ante la opinión pública por "las expresiones racistas del gerente general de la empresa forestal"14. La denuncia de esta Corporación Mapuche, a quién no le pasó desapercibida esta situación, desvía así la atención desde la situación de aeropuerto y la eventual suspensión de los vuelos para la realización del nguillatun, hacia el entramado de ideologías discriminatorias y el proyecto económico representado por las empresas forestales. Amplía la complejidad de la trama intercultural e interétnica y la abre hacia las implicancias de su uso ofensivo y racista, ya no sólo para la convivencia en el territorio, sino también para los actuales marcos del derecho internacional en materias indígenas, los sistemas institucionales que les sustentan - como Naciones Unidas - y a partir de ellos, al sistema de certificación forestal internacional FSC.

La interpelación es directa y enfática por parte de la organización indígena citada: "Exigimos un pronunciamiento oficial y disculpas públicas de (la empresa forestal)... y esperamos un pronunciamiento oficial de FSC Chile acerca de la membresía de esta empresa dirigida por un racista" ${ }^{\prime 2}$. De esta manera, la Corporación Mapuche exige a la representación nacional del sistema de certificación internacional una respuesta acorde a lo que transmite en sus principios, un pleno resguardo a los contenidos que para algunas comunidades mapuche han sido garantía de una nueva oportunidad para la construcción de la convivencia entre las empresas forestales y las comunidades en el centro sur de Chile.

La Agrupación de Ingenieros Forestales para el Bosque Nativo (AIFBN) emite a su vez una queja formal ante FSC Chile y FSC Internacional, el 01 de diciembre de 2014, argumentando que los dichos del ejecutivo forestal son "expresiones contrarias al espíritu y principios básicos del FSC", y solicitan "una investigación y aplicación de la Política de Asociación de la empresa" "16. De acuerdo a esta política, existe un conjunto de actividades "inaceptables" para todas aquellas empresas que voluntariamente se han asociado a FSC, entre las cuales se destacan

las talas ilegales, la violación de los derechos tradicionales y humanos en las operaciones silvícolas, la destrucción de los altos valores de conservación, la conversión significativa de bosques a plantaciones, la introducción de organismos genéticamente modificados en las

\footnotetext{
${ }^{14}$ Corporación Mapuche Pewün Kimun, Denuncia Pública por expresiones racistas, 2014.

${ }^{15}$ Idem.

16 Agrupación de Ingenieros Forestales para el Bosque Nativo, Carta al Director Ejecutivo de FSC Internacional, 2014.
}

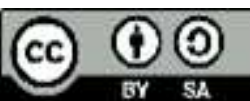


Noelia Carrasco - Ricardo Salas, Inflexiones y dilemas ético - políticos del capitalismo en el Centro Sur de Chile. A propósito de la globalización forestall / Inflections and ethical - political dilemmas of the capitalism in the Center South of Chile. About forest globalization, Revista Izquierdas, 27, abril 2016, ISSN 0718-5049, pp. 105-123

operaciones silvícolas y la violación a cualquiera de los Convenios Fundamentales de la OIT $^{17}$.

En caso de demostrarse que alguna empresa asociada incurre en este tipo de actividad, el Consejo Directivo del FSC puede decidir disociar a dicha empresa del sistema ${ }^{18}$. No obstante, de acuerdo a las notificaciones emitidas por FSC, la denuncia recibida "no constituía razón para procesar la queja de manera formal a través del Sistema de Resolución de Controversias" 19 , no obstante la naturaleza de los comentarios si fue considerada "en contra de los valores y los Principios y Criterios del FSC"20. En los meses siguientes, FSC Internacional solicita a la empresa en cuestión el cumplimiento de las siguientes condiciones: una disculpa pública, una declaración de rechazo al racismo, el desarrollo de proyectos medio ambientales y medidas sociales para compensar a las comunidades indígenas, la inclusión del principio de "cero tolerancia hacia el racismo" y un plan de acciones a implementar por la empresa ${ }^{21}$.

El desenlace de esta denuncia dejó entonces en evidencia lo que identificamos como componentes de la lógica del mercado global contemporáneo, que antepone condiciones y categorías que pretenden regular la producción en el marco de la comprensión oficial del "manejo forestal sustentable". Lo cierto es que los datos del caso mediático estudiado permiten demostrar que esta comprensión es laxa y complaciente, y que antes de tener un rol normativo es paternalista y funcional tanto a la limitada idea de sustentabilidad que profesa, como también y especialmente a las empresas forestales que han demostrado permanentemente grandes dificultades para comprenderla e implementarla de modo coherente. Como se ilustra previamente, la respuesta y la intervención de FSC ante la empresa cuyo representante fue denunciado, fue de carácter correctiva y formativa, en el sentido de propiciar que la empresa se disculpara públicamente e implementara un conjunto de medidas que evidencian a su vez una concepción de los impactos ambientales y sociales de las operaciones forestales en un sentido restringido y estrictamente operativo. Preliminarmente, observamos que más allá del rol naturalmente utilitario que pueda esperarse de instrumentos como la certificación forestal, casos como estos dejan en evidencia la manipulación de sentidos que se ejerce, controlando los discursos y desde ahí generando expectativas de un manejo forestal sustentable que nunca llega.

\section{¿Dilemas éticos o hegemonía del mercado en la conceptualización de la sustentabilidad?}

En un conocido artículo publicado en el año 2000, James O'Connor se preguntaba si “¿Es posible es capitalismo sostenible?"22. En la organización de su planteamiento se evidenciaba la importancia de relativizar y reconocer las diferentes versiones que circulan

\footnotetext{
${ }^{17}$ FSC-POL-01-004 V2-0-ES, Política para la Asociación de Organizaciones con el FSC, 2009.

${ }^{18}$ Idem.

${ }^{19}$ Declaración Pública de FSC. 2015.

${ }^{20}$ Idem.

${ }^{21}$ Línea temporal caso Bosques Cautín. 2015.

${ }^{22}$ James O'Connor, “¿Es posible el capitalismo sostenible?”, Papeles de Población 6:24, Toluca, 2000, 9-35.
} 
Noelia Carrasco - Ricardo Salas, Inflexiones y dilemas ético - políticos del capitalismo en el Centro Sur de Chile. A propósito de la globalización forestall / Inflections and ethical - political dilemmas of the capitalism in the Center South of Chile. About forest globalization, Revista Izquierdas, 27, abril 2016, ISSN 0718-5049, pp. 105-123

en torno a la sostenibilidad, siempre sobre la base de su naturaleza ideológica y política. Desde tal revisión, nos motiva a interrogarnos por el alcance político de la concepción empresarial en torno a la sustentabilidad y a poner nuestra atención en la construcción de otros sentidos que pudieron llevar a la confluencia entre consumidores, ambientalistas, científicos de la conservación, organizaciones indígenas, trabajadores, entre muchos otros actores que hasta ahora han respaldado a FSC. Más allá que desde cada una de estas perspectivas se comparta el principio de no cuestionar al mercado en su funcionamiento capitalista, llama la atención que se mantenga la conformidad con una idea de sustentabilidad limitada al control de los impactos operacionales de la producción forestal.

La única explicación para comprender qué ha mantenido este tipo de alianzas ideológicas y políticas con la lógica empresarial, y en gran medida, ha permitido que el capitalismo transnacional se mantenga revestido de sustentable, es que el discurso de FSC seduce y concede mencionar la importancia de los derechos indígenas y sobre todo, releva fuertemente a los denominados "valores de conservación”. Estos últimos, encantan no sólo a organizaciones locales con fines ambientalistas y con objetivos que reivindican el resguardo de los recursos naturales, sino también a un importante sector del mundo científico ambiental que ha afirmado la importancia de sistemas como FSC ${ }^{23}$. Nos preguntamos entonces, ¿es la sustentabilidad un vehículo del capitalismo global? Ciertamente, la sustentabilidad oficial como la que profesa FSC sirve principalmente a los intereses empresariales y en todo aquello que no afecte a estos intereses. Secundariamente, también sirve a otros intereses, tales como a los derechos indígenas y los intereses de conservación del mundo científico y/o ambientalista. El problema es que mientras estos sectores secundarios no amplíen su crítica y sus exigencias a la fórmula productiva y comercial transnacional que hoy gobierna al mercado y a las sociedades que viven bajo su orgánica, prevalece el control de sentidos, de formas de pensar bajo un supuesto común. Este supuesto es controlado desde un eje que consiente en la importancia de dichos intereses indígenas y ambientalistas, pero no logra relevarlos hasta dar señales de una efectiva evolución hacia otros criterios ético - políticos del mundo y la naturaleza. En suma, no hay avance y siguen sin poder surgir señales serias, ni de acomodo ni ajuste de la economía a los problemas materiales y sustantivos que atraviesan a la vida social.

La interpelación de una organización mapuche y de los especialistas en bosque nativo es implícitamente una solicitud de coherencia con los sentidos y significados que el estándar FSC promueve a través de sus principios y criterios. Lo que deja en evidencia luego, tanto la denuncia como el curso de los hechos es que no hay incompatibilidad valórica entre los dichos del ejecutivo y los contenidos del estándar, es decir, FSC concede que el mal trato a las comunidades indígenas es un acto corregible, como cualquier otro atentado en contra de la naturaleza que puede ser compensado ${ }^{24}$.

En el debate sociopolítico, resulta indiscutible que cada miembro de FSC es libre de pensar y actuar desde el principio básico de la economía actual de las libertades individuales. No obstante, y aunque no se declare explícitamente en ninguna parte, ser miembro de FSC, como de cualquier otra organización internacional, supone la adhesión a

\footnotetext{
${ }^{23}$ Nómina de Membresías y Directorio FSC Chile. 2015.

${ }^{24}$ Criterio 4.5. Estándar para la Certificación FSC de Plantaciones Forestales de Operaciones a Gran Escala. 2010.
} 
Noelia Carrasco - Ricardo Salas, Inflexiones y dilemas ético - políticos del capitalismo en el Centro Sur de Chile. A propósito de la globalización forestall / Inflections and ethical - political dilemmas of the capitalism in the Center South of Chile. About forest globalization, Revista Izquierdas, 27, abril 2016, ISSN 0718-5049, pp. 105-123

ciertos principios y criterios de una ética política y económica que subyacen a la actividad que promueve. Allí se encuentran hoy las bases de la gobernabilidad que busca la economía transnacional en contextos de diversidad cultural, su recurso político de control ideológico y económico local que se pregona en diversas organizaciones. La pregunta que surge entonces es por las características de esta ética y las tramas que hoy organizan y controlan a los saberes que circulan en contextos dominados por el pensamiento transnacional.

Desde nuestro punto de vista científico social, consideramos que FSC - como muchos otros certificados que participan hoy en la regulación de los mercados y el consumo - es un instrumento que incide directamente en los cursos de la economía internacional. Es decir, no es un instrumento decorativo ni mucho menos una simple declaratoria de buenas intenciones. Las auditorias para la evaluación del manejo forestal sustentable que dan como resultado la obtención o conservación del certificado por parte de las empresas, indagan - entre otros aspectos - en el modo en que éstas formulan su relación con las comunidades indígenas, y buscan verificar precisamente que los contenidos del discurso del estándar se transfiera a prácticas respetuosas y sustentables. El hecho que hoy en día las principales empresas forestales del país se encuentren certificadas y más aún, que una de las más grandes empresas haya recibido recientemente un premio internacional por "trayectoria sustentable" otorgado por la misma casa certificadora que le otorgó el sello FSC, reafirma la hegemonía ideológica de la sustentabilidad capitalista oficial ${ }^{25}$. Frente a esto se han sucedido desde 2011 un conjunto de críticas a nivel nacional e internacional, que apuntan a cuestionar no sólo la supuesta sustentabilidad de los monocultivos a gran escala sino también la credibilidad de sistemas como FSC, considerando que previo a su despliegue en Chile éste constituía una suerte de esperanza para el control del comportamiento de las empresas forestales.

Hay entonces un desafío que impone la propia economía de libre mercado a través de este tipo de instrumentos, que según nuestra interpretación buscan organizar la gestión de las externalidades de la producción forestal, implicando en ello intereses, proyecciones, valores y desafíos que trascienden con creces la misión exclusiva de las empresas. En definitiva, se evidencia que el manejo forestal sustentable se enfrenta a desafíos que no son únicamente operacionales, y que por tanto, no se resuelven únicamente con "buenas prácticas". Dado lo anterior, consideramos que frente a problemas como los que hoy en día atraviesan a la región forestal en Chile, el sistema FSC se ha mostrado insuficiente principalmente por dos razones. En primer lugar, porque sus contenidos no logran orientar a que las empresas controlen de modo efectivo sus impactos operacionales y se ubiquen en una posición colaborativa en el territorio, lo que ha favorecido un control reactivo a los problemas y la profundización de la postura impositiva de las empresas en el control territorial. En segundo término, al propiciar la colectividad en torno a un concepto hegemónico de sustentabilidad, el sistema FSC ha permitido oscurecer las diferencias que puedan darse en torno a su comprensión, y más aún, ha negado la posibilidad de dialogar en torno a lo que los diversos actores que le sostienen con su membrecía puedan pensar y aspirar respecto a la economía y la conservación de los recursos naturales. Se ha instalado

\footnotetext{
${ }^{25}$ CMPC. Reconocimiento mundial por gestión y desarrollo sustentable, 2015.
} 
Noelia Carrasco - Ricardo Salas, Inflexiones y dilemas ético - políticos del capitalismo en el Centro Sur de Chile. A propósito de la globalización forestall / Inflections and ethical - political dilemmas of the capitalism in the Center South of Chile. About forest globalization, Revista Izquierdas, 27, abril 2016, ISSN 0718-5049, pp. 105-123

así como un discurso dominante, que opera y atrapa a lógicas diversas bajo el supuesto objetivo común del manejo forestal sustentable.

\section{Inflexiones ético-políticas del capitalismo y conflictos interculturales}

Las inflexiones y dilemas ético-políticos que trae el nuevo discurso de la certificación forestal en las plantaciones que se expanden en los territorios de la Macrorregión sur de Chile son parte del escenario del capitalismo global y se encuentran en diversos territorios y continentes. Se podría comprender la especificidad chilena de este proceso a partir de la tensión señalada por T. Moulián cuando indica que las modernizaciones empresariales del neoliberalismo han transformado económica, política y culturalmente el país, en medio de costos socioculturales que no logran dimensionarse, conformando parte del mito del país exitoso y emprendedor, pero que continúan muchas de sus antiguas prácticas socioculturales y políticas. Por esta razón dentro de las primeras inflexiones a considerar es cómo en décadas de procesos de una sociedad neoliberalizada no se han transformado muchas de las viejas prácticas de la burguesía y del empresariado, lo que permite entender que se mantengan en una economía global, las formas estereotipadas, los prejuicios y las diversas asimetrías transmitidas hacia el imaginario del otro étnico. Al mismo tiempo cabe considerar la permanencia de focos de resistencia desde otras lógicas y a partir de imaginarios que se creían perdidos. Tal como lo ha formulado el dirigente mapuche, $\mathrm{H}$. Llaitul acerca de los nuevos sentidos de la invasión de los territorios y que hoy puede ser ampliado para todos los territorios indígenas

Hoy tiene lugar una tercera invasión. Los mapuches que aún sobreviven en sus tierras son diariamente invadidos por las forestales, las empresas hidroeléctricas, las exploraciones y las explotaciones mineras. Es el sistema capitalista, son las transnacionales. Para los nuevos invasores, los mapuche tienen derecho a existir sólo como mano de obra, como individuos que ofrecen su fuerza de trabajo a las grandes empresas, pero no tienen derecho a existir como pueblo, como nación (Llaitul \& Arrate, $2013: 57)^{26}$.

La segunda inflexión deriva de la relación entre los sistemas sociales y los sistemas simbólicos donde se instala la cuestión ético-política. En los territorios del centro sur y frente a la expansión forestal que coloniza dichas tierras dentro de la lógica capitalista se generan ciertamente procesos de crítica, de resistencia que se juegan al interior de complejos tejidos conflictuales e intersubjetivos de vida. Estos tejidos entrecruzan valores, símbolos y prácticas que están lejos de reducirse producto de las fórmulas procedimentales que llevan adelante los procesos de certificación forestal. En tales procesos se muestra más bien la capacidad de las empresas de actualizarse frente a las exigencias de un "standard" derivado del mercado global, pero sin lograr dar cuenta de la vitalidad y la especificidad del movimiento de las culturas indígenas, populares y campesinas que puede implicar un cuestionamiento al capitalismo global. La evolución mediática del caso estudiado a nuestro

${ }^{26}$ Ibid. 
Noelia Carrasco - Ricardo Salas, Inflexiones y dilemas ético - políticos del capitalismo en el Centro Sur de Chile. A propósito de la globalización forestall / Inflections and ethical - political dilemmas of the capitalism in the Center South of Chile. About forest globalization, Revista Izquierdas, 27, abril 2016, ISSN 0718-5049, pp. 105-123

entender, muestra algo central para asumir una mirada integral de los conflictos y no quedarse sólo en una perspectiva reductivamente socio-económica. Para ello es clave reconocer las significaciones y los sentidos que tienen hoy los bienes simbólicos y el poder creciente que tienen las redes sociales que pueden servir tanto a la expansión de una cultura mediática poco crítica, como potenciar formas de resistencias y de búsquedas de otros sentidos que no son los propiamente vehiculados por el capitalismo. En las contradicciones manifestadas en el caso estudiado quedan expuestas las tensiones y contradicciones que se viven en las regiones inter-étnicas como es el caso del mundo mapuche, y que los procesos de certificación no reconocen como tales.

Moulián ha propuesto una interesante relación entre las dinámicas culturales del neoliberalismo y las formas que asume la política chilena, cuando se produce la intersección entre militares, intelectuales neoliberales y empresarios nacionales e internacionales $^{27}$. Esta tesis de T. Moulián es cercana de una teoría crítica de la cultura de la modernidad, donde las posiciones teóricas de fondo habría que buscarlas del lado de la filosofía gramsciana. Esto quiere decir, una donde se busca indagar y destacar formas, ideas y nociones que conforman el arsenal cognitivo-explicativo desde el cual las diversas clases o grupos pretenden dar cuenta de sus prácticas y al mismo tiempo, universalizarlas. Tales observaciones permiten desprenderse de una mirada neutra de las transformaciones culturales de las comunidades de vida porque precisamente permiten repensar el "transformismo" que ha vivido el Chile actual, negando las efectivas dinámicas y tensiones entre la cultura de élite y las culturas comunitarias. Esto aporta a la crítica ácida del consumismo y de la pasividad del ciudadano-card, y deja en mejores condiciones a las ciencias sociales para dar cuenta de las dinámicas de esas otras culturas invisibilizadas.

En la ética contemporánea varias corrientes han intentado elaborar apoyos teóricos acerca de la ética del desarrollo y de la ética de las empresas ${ }^{28}$. Algunas se han derivado de las éticas aplicadas o han intentado avanzar en ciertos criterios ético-políticos que contribuyan a la responsabilidad social de las empresas. En muchas de estas perspectivas lo que no se logra aclarar del todo es la dimensión ideológica del desarrollo ni menos aún entender las contradicciones ético-políticas de las multinacionales al interior del modelo de desarrollo neoliberal actual, v.g. Así lo destacan diversos trabajos donde aparecen los mitos e imaginarios del milagro chileno, que no logran superar el racismo, la discriminación y la violencia. En este plano estos enfoque éticos aludidos no logran captar que el capitalismo global no trae nuevos imaginarios de igualdad y de justicia sino que más aun, lejos de propiciar su revisión, profundiza la desigualdad estructural que, resumiendo, sigue operando en el juego imaginario de las elites que vacila entre civilización y barbarie y el discurso del mestizaje que se sigue plasmando en una visión multicultural dominante que se sigue operacionalizando por parte del Estado en los territorios inter-étnicos en cuanto no amenacen la identidad unitaria o el desarrollo nacional ${ }^{29}$.

Las nuevas cuestiones de la ética en tiempos de capitalismo se asocian también necesariamente al papel e influencia de las redes sociales y de los grandes medios de comunicación. Esto es innegable en el vínculo entre el capitalismo y los procesos de

\footnotetext{
${ }^{27}$ Tomás Moulián, Chile Actual: Anatomía de un mito, Santiago, LOM Ediciones, 1997.

${ }^{28}$ Cristian Parker, Ética, Democracia y Desarrollo Humano, Santiago, LOM Ediciones, 1998.

${ }^{29}$ Richards, op. cit.
} 
Noelia Carrasco - Ricardo Salas, Inflexiones y dilemas ético - políticos del capitalismo en el Centro Sur de Chile. A propósito de la globalización forestall / Inflections and ethical - political dilemmas of the capitalism in the Center South of Chile. About forest globalization, Revista Izquierdas, 27, abril 2016, ISSN 0718-5049, pp. 105-123

globalización ${ }^{30}$. Los análisis ético- políticos de las relaciones interculturales demuestran en casi todos los casos ejercicios de resignificación de los productos culturales del capitalismo. Son los sujetos y colectivos emergentes que no se satisfacen con los desechos de significación que proponen las industrias mediáticas, y van re-elaborando sus propuestas culturales de resistencias específicas a partir de los contenidos que éstos difunden. Hace unos pocos años nadie habría pensado en considerar dichas tensiones a partir de las opiniones que se transmiten en las redes sociales o en las entrevistas de dirigentes de movimientos alternativos. El punto crucial no es sólo indicar que tales procesos de resignificación existen, sino cómo ellos se tematizan dentro de nuevas propuestas sociales y culturales asociados a los contextos mismos, y logran cuestionar la lógica inherente, en este caso, a las certificaciones internacionales asociadas a la sustentabilidad forestal.

El caso estudiado propone una perspectiva crítica acerca de la cultura y la identidad en estos territorios interétnicos donde hay que visibilizar los saberes encubiertos. A nuestro entender, la ética reinterpretada desde los conflictos interculturales continúa siendo un elemento central para redefinir el sentido humano de las diversas prácticas culturales. Esto se enriquece mucho más aun, desde la comprensión de las unidades geoculturales que van re-significando las diferentes identidades en cuanto que ellas entregan las posibilidades de encontrar otro-lugar simbólico desde donde cuestionar el punto de vista de la facticidad universalista de las empresas (Cf. Weichan de H. Llaitul).

Estas plurales y diversas formas de resistencia de los movimientos sociales, de las etnias y de los diferentes sectores postergados por un modelo económico a través de los medios e instrumentos que produce el propio capitalismo nos muestran la grandes contradicciones: ya que aunque las certificaciones traen beneficios para las empresas multinacionales, el propio proceso genera una atención crítica hacia las empresas certificadas. Esto nos obliga a repostular nuevamente una dimensión eminentemente conflictiva de las sociedades concretas porque ellas son parte de las formas de vivir y convivir definidas por lo general en el disenso cultural, en la asimetría histórica y en el trasfondo de una lógica de la negación. En otras palabras, en la cuestión debatida encontramos interpretaciones de la experiencia histórica de los invisibilizados, derrotados y de las minorías que se abre hoy a las posibilidades de un nuevo paradigma económico político ligado al reconocimiento de los otros, pero sabiendo que las experiencias culturales están profundamente marcadas por la experiencia de la injusticia y también por la exclusión de los otros diferentes. Esta forma plural y conflictiva de la ética ya no se hace autocentrada a un grupo o a una clase, sino que es relacional porque se enlaza con la constitución de una universalidad situada, que se consolida a través de una nueva figura del polilogos y que aspira hacerse común como proyecto histórico y cultural.

Recapitulemos, señalando que la relevancia de los dilemas ético-políticos refieren a la consolidación epistémica de una reflexividad conflictiva, la cual, como signo de este tiempo nos abre hacia lo que se denomina el "diálogo de saberes". Esto no es sólo teórico, sino que es una opción ético-política por la emergencia de sujetos en interacción y subjetividades comunitarias, y no sólo como usuarios aislados o microcomunidades vinculadas a la autoapropiación de productos tecnológicos. Estamos, a pesar de una

${ }^{30}$ Néstor García Canclini, Diferentes, Desiguales y Desconectados. Mapas de la Interculturalidad, Buenos Aires, Gedisa, 2004. 
Noelia Carrasco - Ricardo Salas, Inflexiones y dilemas ético - políticos del capitalismo en el Centro Sur de Chile. A propósito de la globalización forestall / Inflections and ethical - political dilemmas of the capitalism in the Center South of Chile. About forest globalization, Revista Izquierdas, 27, abril 2016, ISSN 0718-5049, pp. 105-123

intelectualidad desencantada y sin militancia -como ocurre en muchos países-, siempre en mundos de vida con sujetos históricos, en medio de movimientos sociales y étnicos en que la acción es el verdadero núcleo de la discusión con el postmodernismo. La tarea de una ética intercultural no es sólo dar cuenta de valores humanos en interacción y propuestas de alternativas universalizables sino que propender también a elaborar pensamientos depositarios de las experiencias socio-políticas de lucha y de resistencia. En este plano las últimas décadas ayudan a comprender las profundas asimetrías y las lógicas de la negación que afectan desde hace siglos a las comunidades indígenas, afroamericanas, campesinas y urbano-populares. Esto ha permitido demostrar que el capitalismo a pesar de su arrolladora intervención en el seno de la cultura, no ha logrado su propósito, ya que las eticidades de luchas están aún presentes.

\section{Conclusiones}

A partir de este debate fue posible abrir y discutir nuevas preguntas para profundizar en la comprensión de la madeja interétnica atravesada por los significados instalados en quienes conducen la gestión de las empresas forestales que participan de la economía global, de algún modo se abre una caja de pandora de lo que se denomina "el desarrollo económico en el Centro Sur de Chile". El caso aquí analizado nos muestra que el racismo y el descrédito pueden estar íntima y subjetivamente integrados a una misma ética económica y comercial, constituyéndose en una amenaza brutal para el adecuado desarrollo cultural y económicamente diverso que requieren estos territorios. Al mismo tiempo, el análisis nos ha permitido demostrar que la hegemonía ideológica del capitalismo global pasa hoy en día por el ejercicio de seducción que ejercen ideas como la sustentabilidad, la cual opera de manera audaz y definitiva no sólo en la instalación de verdades, sino también en el impedimento a que otras elaboraciones o versiones sobre la economía y los recursos naturales se despliegue con naturalidad y riqueza ${ }^{31}$. Sistemas como FSC si bien pudieron haber jugado un rol en contextos de fricción entre empresarios y consumidores, al globalizar una fórmula para comprender y orientar al manejo forestal sustentable, hoy en día cierra la posibilidad a que la sustentabilidad sea revisada y definida en términos de la diversidad de intereses que pueda haber sobre los recursos.

Desde las miradas de la antropología de la globalización y de la filosofía intercultural pensadas desde el territorio afecto a la economía transnacional, se observa en el sistema FSC un ejercicio performativo del capitalismo, que hace cosas con las palabras y que además, permite que los sujetos y las comunidades de vida puedan (o no) converger en significados y valores. Constituye además un recurso que articula prácticas económicas y políticas para, finalmente, permitir o impedir la convivencia respetuosa en la vida cotidiana.

Desde este prisma interpretamos que los planteos referidos de un ejecutivo forestal transmiten también una determinada "visión de la realidad", convicciones profundas y las certezas subjetivas y pseudo-verdades a partir de las cuales se vive, desde el rechazo y el desprecio, la convivencia con los mapuche en un mismo territorio. Frente a ello

\footnotetext{
${ }^{31}$ Enrique Leff, La opción por la vida. Imaginación sociológica e imaginarios sociales en los territorios ambientales del sur, México, Siglo XXI, 2014.
} 
Noelia Carrasco - Ricardo Salas, Inflexiones y dilemas ético - políticos del capitalismo en el Centro Sur de Chile. A propósito de la globalización forestall / Inflections and ethical - political dilemmas of the capitalism in the Center South of Chile. About forest globalization, Revista Izquierdas, 27, abril 2016, ISSN 0718-5049, pp. 105-123

evidenciamos las limitaciones del constructo conceptual y operativo denominado "manejo forestal sustentable" y sus dificultades para hacer frente a las actuales complejidades del escenario en que se despliega la industria forestal. Concluimos al respecto la eventual agonía o urgente evolución de este tipo de instrumentos del mercado, la que estaría determinada tanto por su corto alcance en materia de atención a eventos como el descrito como también por su incapacidad de evolucionar hacia escenarios que incidan de manera más evidente en el control de la producción. A partir de esto, observamos que sistemas como FSC no sólo tienden a ser inoperantes frente a los problemas reales que afectan a la actividad productiva e industrial sino más gravemente aun, tiende a favorecer la promoción de comprensiones hegemónicas de la sustentabilidad a partir de lo cual subordina silenciosamente a otras comprensiones de la realidad cultural y natural.

Frente a lo anterior, cobran especial valor las denuncias de organizaciones que con este gesto parecen reafirmar el alcance y la confianza en FSC frente a problemáticas de orden ético y social como la descrita. Observamos allí una oportunidad para que la matriz ideológica de la sustentabilidad capitalista se revise y actualice en función de desafíos concretos y locales, abriendo paso al reconocimiento y la discusión de los desafíos que actualmente atraviesan al desarrollo económico en el centro Sur de Chile, a saber, la construcción de disposiciones, comprensiones y lenguajes concordantes con concepciones diversas de la sustentabilidad. Esta sería la base primera de una ética de los acuerdos, lo que Maliandi ha llamado oportunamente, la búsqueda de éticas convergentes (2010) y que exige entre otras cosas, contar con ciudadanías diversas e informadas y vigilantes, que ayuden como en este caso, a destrabar nudos de la convivencia interétnica, y que impele como propone Hale a que las investigaciones académicas asuman los desafíos de un conocimiento comprometido ético-políticamente.

La comprensión y gestión de la sustentabilidad en el sector forestal seguirá siendo controlada exclusivamente por el pensamiento empresarial, mientras no se ponga exhaustiva atención a los impactos materiales y simbólicos de las plantaciones y la industria a nivel local. Sólo desde allí puede hacerse posible actualizar el discurso respecto a lo que socialmente se requiere para controlar al mercado, y generar instrumentos más efectivos que incidan sobre los problemas de vivencia y convivencia que marcan a nuestros territorios. Dado lo anterior, se vuelve más urgente la reformulación de la comprensión revisionista del capitalismo global, y en ello, los actores y sectores que hasta ahora han defendido derechos indígenas y valores de conservación dentro del marco oficial, debiesen poder avanzar hacia el reconocimiento de nuevos indicadores. El ejercicio de control ideológico también puede ser intervenido y gestionado, siempre y cuando exista intención de hacer contribuciones efectivas e incidentes en la gobernanza capitalista contemporánea.

\section{Bibliografía}

\section{Fuentes Impresas}

Marc Abeles, Antropología de la Globalización, Ediciones del Sol, Buenos Aires, 2012. 
Noelia Carrasco - Ricardo Salas, Inflexiones y dilemas ético - políticos del capitalismo en el Centro Sur de Chile. A propósito de la globalización forestall / Inflections and ethical - political dilemmas of the capitalism in the Center South of Chile. About forest globalization, Revista Izquierdas, 27, abril 2016, ISSN 0718-5049, pp. 105-123

Noelia Carrasco, "Horizontes de la reflexividad etnográfica. Revelaciones y tensiones para el estudio antropológico del desarrollo en Chile”, en Tabula Rasa 17, Bogotá, 113-129, 2012.

Santiago Castro - Gómez y Ramón Grosfoguel, "Prólogo. Giro decolonial, teoría crítica y pensamiento heterárquico", Santiago Castro - Gómez y Ramón Grosfoguel (Eds), El giro decolonial. Reflexiones para una diversidad epistémico más allá del capitalismo global. Bogotá, Siglo del Hombre Editores, 2007, 9-24.

Comunidad de Historia Mapuche, Ta iñfijkerakizuameluwün. Historia, colonialismo y resistencia desde el país Mapuche, Ediciones Comunidad de Historia Mapuche, 2012 (1ª Edición), 2013 (2da Edición).

Daniel Dominguez, Anne Beaulieu, Adolfo Estalella, Edgar Gómez, Bernt Schnettler y Rosie Road, Etnografía Virtual, Forum Qualitative Sozialforschung / Forum: Qualitative Social Research, 8 (3).

Arturo Escobar, "Bienvenidos a cyberia. Notas para una antropología de la cibercultura", Revista de Estudios Sociales $N^{\circ} 22,2005,15-35$.

Néstor García Canclini, Diferentes, Desiguales y Desconectados. Mapas de la Interculturalidad, Buenos Aires, Gedisa, 2004.

Charles Hale, "Activist Research v. Cultural Critique: Indigenous Land Rights and the Contradictions of Politically Engaged Anthropology." Cultural Anthropology 21, № 1 (2006): 96120.

Enrique Leff, La opción por la vida. Imaginación sociológica e imaginarios sociales en los territorios ambientales del sur, México, Siglo XXI, 2014.

Sandra López y Luis Nitrihual, Vidas de Papel. Negocio de la Madera y Conflicto Intercultural en Chile, Editorial Universidad de la Frontera, Temuco, 2014.

Héctor Llaitul y Jorge Arrate, WEICHAN. Conversaciones con un weychafe en la prisión política, Ceibo Ediciones, Santiago, 2013.

Ricardo Maliandi, Ética Convergente. Fenomenología de la conflictividad, Buenos Aires, Los Cuarenta, 2010.

George, E. Marcus, "Etnografía en/del sistema mundo. El surgimiento de la etnografía multilocal", Alteridades Vol. $11 \mathrm{~N}^{\circ} 22,2001$.

Tomás Moulián, Chile Actual: Anatomía de un mito, Santiago, LOM Ediciones, 1997

James O’Connor, “¿Es posible el capitalismo sostenible?”, Papeles de Población 6:24, Toluca, 2000, 9-35

Marcel Oppliger, Los chilenos olvidados. Hablan las víctimas del conflicto en La Araucanía, Santiago, Ril Editores, 2013. 
Noelia Carrasco - Ricardo Salas, Inflexiones y dilemas ético - políticos del capitalismo en el Centro Sur de Chile. A propósito de la globalización forestall / Inflections and ethical - political dilemmas of the capitalism in the Center South of Chile. About forest globalization, Revista Izquierdas, 27, abril 2016, ISSN 0718-5049, pp. 105-123

Cristian Parker, Ética, Democracia y Desarrollo Humano, Santiago, LOM Ediciones, 1998

Patricia Richards, Race and the Chilean Miracle: Neoliberalism, Democracy and Indigenous Rights, Pittsburgh, University of Pittsburgh Press, 2013.

Ricardo Salas, Ética intercultural, Quito, Abya-Yala, 2006.

Ricardo Salas y Fabien Le Bonniec (eds.), Les mapuches à la mode. Modes d'existence et de resistance au Chili, en Argentine et au-delà, Paris, L'Harmattan, 2015.

Tito Tricot, Palabras de tierra: crónicas de resistencia mapuche, Ceibo Ediciones, Santiago, 2014.

\section{Documentos}

Estándar para la Certificación FSC de Plantaciones Forestales de Operaciones a Gran Escala. 2010. STDPL- 201205 / 311209

Política para la Asociación de Organizaciones con el FSC. FSC-POL-01-004 V2-0-ES

\section{Fuentes electrónicas}

Agrupación de Ingenieros Forestales para el Bosque Nativo, Carta al Director Ejecutivo de FSC Internacional, 2014. http://bosquenativo.cl/respaldo/index.php?option=com_k2\&view=item\&id=1274: carta-enviada-aldirectorio-de-fsc-internacional-y-fsc-chile\&Itemid=51

Noelia Carrasco y Ricardo Salas, De aviones, nguillatunes y otros dilemas ético-políticos. Inflexiones acerca del desarrollo en la Araucania.

http://observatoriodecide.cl/2014/12/16/de-aviones-nguillatunes-otros-dilemas-etico-politicosinflexiones-acerca-del-desarrollo-en-la-araucania/

CMPC. Reconocimiento mundial por gestión y desarrollo sustentable, 2015. http://www.cmpc.cl/?p=6224

Corporación Mapuche Pewün Kimun, Denuncia Pública por expresiones racistas, 2014. http://www.mapuche.info/print.php?pagina $=4748$

Declaración Pública de FSC. 2015 https://cl.fsc.org/preview.informe-de-progreso-de-bosques-cautn.a-119.pdf

Línea temporal caso Bosques Cautín. 2015

https://cl.fsc.org/sala-de-noticias.58.25.htm

Nómina de Membrecías y Directorio FSC Chile. 2015

https://cl.fsc.org/membresa-fsc-chile.66.htm 